\title{
Development of a regional flood frequency estimation model for Pilbara, Australia
}

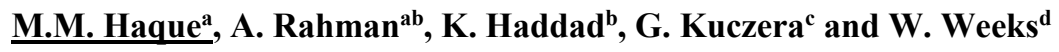 \\ ${ }^{a}$ Institute for Infrastructure Engineering, Western Sydney University \\ ${ }^{b}$ School of Computing, Engineering and Mathematics, Western Sydney University \\ ${ }^{c}$ University of Newcastle \\ ${ }^{d}$ Private Consultant
}

Email:m.haque@westernsydney.edu.au

\begin{abstract}
This paper presents the development of regional flood frequency estimation (RFFE) models for Pilbara, Western Australia as a part of Australian Rainfall and Runoff (ARR) revision. The Pilbara is an economically important arid region, which is rich in natural resources and mining activities. A total of 11 catchments are selected from the Pilbara region to develop the RFFE models. The selected catchments are arid with average annual rainfall values are in the range of 200 and $350 \mathrm{~mm}$. For each of the selected catchments, flood quantiles are estimated for 6 annual exceedance probabilities (AEPs), which are 50\%, 20\%, 10\%, 5\%, $2 \%$ and $1 \%$ using two estimation approaches: (i) annual maximum flood series (AMS): Log Pearson Type 3 (LP3) distribution-Bayesian procedure and (ii) partial duration series (PDS) (with average number of events per year equal to 0.5): Generalised Pareto distribution and L moments procedure. The AMS consists of maximum discharge value in each calendar year; however, the PDS consists of all the independent peak flows over a certain threshold. Two different RFFE models are developed (using AMS and PDS data) using an index flood method where the $10 \%$ AEP flood quantile $\left(Q_{10}\right)$ is used as the index variable and a dimensionless growth factor for AEP of $x \%\left(\mathrm{GF}_{x}\right)$ is used to estimate $Q_{x}$ (where, $x=50 \%, 20 \%, 10 \%, 5 \%, 2 \%$ and $1 \%$ ). The prediction equation for the index flood is developed using an ordinary least squares regression with two predictor variables (catchment area and design rainfall intensity). The results demonstrate that the performance of the two RFFE models is quite similar. For AEPs of $50 \%$ to $1 \%$, the absolute median relative error values of the estimated flood quantiles are found to be in the range of $23 \%$ to $46 \%$ and $42 \%$ to $56 \%$ for AMS and PDS based RFFE models, respectively. The results reveal that both the models are able to generate flood quantiles with a good accuracy; however the AMS-based RFFE model outperforms the PDS-based model.
\end{abstract}

Keywords: Pilbara, RFFE, ARR, arid region, semi-arid region, floods 


\section{INTRODUCTION}

About three quarters of Australian land is considered to be semi-arid and arid where mean annual rainfall is very low. Several Australian studies (e.g. Pilgrim et al, 1988; Ruprecht, 1996; Cordery, 2004) have demonstrated that these arid and semi-arid areas have noticeably different flood hydrology than the humid areas. In these areas, rainfall is highly variable and dry antecedent conditions often lead to little or no runoff from majority of the rainfall events. However, even in these semi-arid and arid areas, severe floods do happen causing significant damage. The geomorphology of the semi-arid and arid areas is distinctly different to the humid areas, which is characterised by a shallow stream system with ill-defined and non-perennial channels that shift courses erratically, high transmission loss, lack of vegetation and high erosion rate (Zaman et al., 2012).

The national guideline for flood estimation in Australia, Australian Rainfall and Runoff (ARR1987) developed regional flood frequency analysis (RFFA) methods for the semi-arid and arid areas of Australia using streamflow data from a handful of catchments (I. E. Aust., 1987). Since the publication of ARR1987, there has been no update of these RFFA methods. More recently, the National Committee on Water Engineering (Engineers Australia) has initiated upgrading the regional flood methods in Australia. In this regard, under Project 5: Regional Flood Methods, significant research endeavours have been carried out (e.g. Rahman et al., 2009, 2011; Palmen and Weeks, 2011; Haddad and Rahman, 2012; Zaman et al., 2012; Haque et al., 2014, Micevski et al., 2015; Rahman et al., 2015). In the ARR Project 5, the semi-arid and arid areas have been separated from the higher rainfall areas by $500 \mathrm{~mm}$ mean annual rainfall (MAR) contour line (i.e. if the MAR is less than $500 \mathrm{~mm}$, the area is considered to be semi-arid and arid). The semi-arid and arid areas have also been divided into two regions, (i) Pilbara region in Western Australia and (ii) other arid areas (Rahman et al., 2015).

The Pilbara is an important mining region in Western Australia. It is often recognised as the engine room of the nation due to its massive reserve of natural resources (e.g. iron ore, base metals, oil and gas). Being one of the world's most ancient natural landscapes covering around $500,000 \mathrm{~km}^{2}$, it is also considered as a region of high environmental significance (HVAC\&R Nation, 2015). However, in this area, stream gauging records are very limited to perform hydrological and flood frequency analyses (Weeks et al., 2015). In addition, there has been limited flood frequency analysis. Rahman et al. (2012a) investigated the flood frequency analysis in Pilbara area using the PDS data and Quantile Regression Technique (QRT).

Rahman et al. (2012b) and Zaman et al. (2012) investigated the flood frequency analysis for the semi-arid and arid areas of Australia by forming a single fixed region with all the arid catchments (i.e. 57 catchments in Rahman et al. (2012b) and 45 catchments in Zaman et al. (2012)). They adopted the index flood method based on the PDS data similar to ARR1987. Flavell (2012) developed a flood estimation model for the Pilbara region using PDS data from 16 catchments by adopting a multiple linear regression and index flood method. For smaller flood quantiles ( $50 \%$ to $5 \% \mathrm{AEPs}$ ), he adopted a multiple linear regression technique to estimate design floods and for higher flood quantiles ( $2 \%$ and $1 \%$ AEPs), a frequency factor based on $5 \%$ AEP was used. Davies and Yip (2014) developed flood estimation models based on the index flood method where design discharge for AEP of $20 \%$ was used as the index flood. They used the annual maximum series (AMS) data from 10 catchments including 5 from Gascoyne region and 5 from Pilbara region in Western Australia. They grouped the catchments based on the catchment areas (small catchments: up to $1000 \mathrm{~km}^{2}$, medium catchment: $1000-10,000 \mathrm{~km}^{2}$ and large catchment: more than $10,000 \mathrm{~km}^{2}$ ) and developed three prediction equations.

The focus of this study is to develop a RFFE model for Pilbara based on the most up-to-date flood data. It compares the AMS and PDS series based RFFE models and recommends a RFFE model for the Pilbara region. The remainder of the paper is organised as below. Study area and data are presented in Section 2, which is followed by presentation of results and conclusion.

\section{STUDY AREA AND DATA}

The Pilbara region, located within $20-24^{\circ} \mathrm{S}$ and $115-122^{\circ} \mathrm{E}$, is generally hot and dry. Seasonality in climate is characterised with hot summers (average daily minimum and maximum temperatures are around $25^{\circ} \mathrm{C}$ and $36^{\circ} \mathrm{C}$, respectively) and mild winters (average daily minimum and maximum temperatures are around $12^{\circ} \mathrm{C}$ and $27^{\circ} \mathrm{C}$ ) (Reeves et al., 2007). Rainfall is highly variable and localised, and mainly happens during the summer months. This region is also subject to cyclones and thunderstorms during the summer months. Being an arid region, the annual potential evaporation is about 10 times higher than the annual rainfall (i.e. evaporation to rainfall ratio: 10 to 1 ). 
In the ARR Project 5, higher rainfall areas of Australia have been divided into five different regions (Regions 1 to 5), and the semi-arid and arid areas have been divided into two different regions (Regions 6 and 7) where Region 6 is the Pilbara region. To develop the data set for RFFE 2015, an upper limit of catchment size of $1,000 \mathrm{~km}^{2}$ was adopted and the cut-off record length was selected as 19 years to maximise the number of catchments. A total of 11 catchments from the Pilbara region (Table 1) satisfy the criteria. The rating curves were examined for these stations as part of data quality check; however, no station in Pilbara was removed based on rating curve extrapolation error due to the availability of very few catchments in this region.

The selected catchments have an average annual rainfall in the range of 200 to $350 \mathrm{~mm}$. The catchment areas range from 0.1 to $885 \mathrm{~km}^{2}$ (median: $174 \mathrm{~km}^{2}$ ) and streamflow record lengths for AMS series range from 26 to 33 years (median: 28 years). Both PDS and AMS data of the selected 11 catchments have been extracted and utilised to develop RFFE models. During extraction of PDS data, the average number of events per year was set as 0.5 . In extracting the AMS and PDS, only the good quality data were considered.

\section{METHOD}

At-site flood quantiles are estimated adopting two different models: (1) AMS model where FLIKE software (Kuczera, 2001) is used to fit the LP3 distribution with the Bayesian procedure (Rahman et al., 2015); and (2) PDS model where Generalised Pareto distribution and L moments procedure are adopted. Flood quantiles are estimated for 6 different annual exceedance probabilities (AEPs) (i.e. 50\%, 20\%, 10\%, 5\%, 2\% and 1\%).

In order to develop the RFFE model, an index flood method is adopted where the $10 \%$ AEP flood quantile $\left(Q_{10}\right)$ is used as the index variable. A dimensionless growth factor for AEP of x\% is used to estimate $Q_{x}$, where $x=50 \%, 20 \%, 10 \%, 5 \%, 2 \%$ and $1 \%$ AEPs. The prediction equation is developed for $Q_{10}$ as a function of two predictor variables (catchment area and design rainfall intensity of 6-hour duration and 50\% AEP).

Table 1. Selected study catchments from Pilbara (Western Australia).

\begin{tabular}{|c|c|c|c|c|c|}
\hline $\begin{array}{l}\text { Station } \\
\text { ID }\end{array}$ & Station name & River name & $\begin{array}{c}\text { Catchment area } \\
\left(\mathrm{km}^{2}\right)\end{array}$ & $\begin{array}{c}\text { AMS record length } \\
\text { (years) }\end{array}$ & $\begin{array}{l}\text { Period of } \\
\text { record }\end{array}$ \\
\hline 701003 & Nokanena Brook & Wootachooka & 235.2 & 28 & $1973-2000$ \\
\hline 701006 & Buller & Buller & 33.9 & 27 & $1974-2001$ \\
\hline 701601 & Wearbe & $\begin{array}{c}\text { Nokanena Brook } \\
\text { Catch } \\
\end{array}$ & 0.1 & 29 & $1971-1999$ \\
\hline 706207 & Mt Samson & Hardey & 250.3 & 33 & $1968-2001$ \\
\hline 707001 & Palra Springs & Robe & 174.3 & 32 & 1968 - 1999 \\
\hline 708009 & Fish Pool & Kanjenjie Ck Trib. & 41.1 & 28 & $1973-2001$ \\
\hline 708227 & Recorder Pool & Portland & 553.4 & 33 & $1968-2001$ \\
\hline 709010 & Pincunah & Turner & 885 & 27 & $1985-2012$ \\
\hline
\end{tabular}

\section{RESULTS}

The fitted flood frequency curves at each of the selected gauging stations for the AMS and PDS cases are checked visually (examples can be seen in Figures 1 and 2). The fit is found to be better generally for the AMS case than the PDS one - this is largely attributed to the censoring of potentially influential low flows in the Bayesian AMS procedure. The median growth factors are estimated to be 0.214, 0.614, 1.00, 1.456, 2.116 and 2.639 for AEPs of $50 \%, 20 \%, 10 \%, 5 \%, 2 \%$ and $1 \%$ AEPs (for the AMS case). The median growth factors for the PDS case are $0.329,0.858,1.00,1.813,2.404$ and 3.192 , respectively. 
Haque et al., Development of a regional flood frequency estimation model for Pilbara, Australia
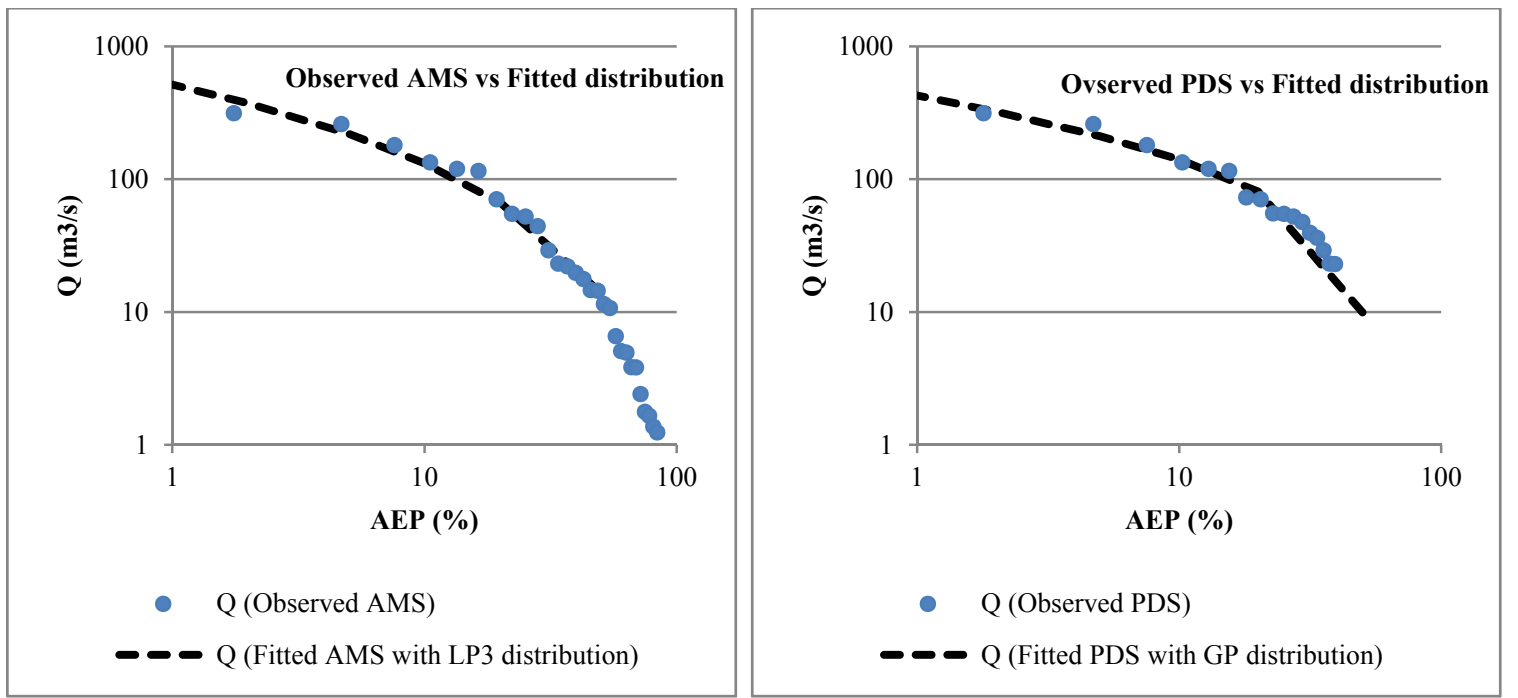

Figure 1. Fitted probability distributions for the AMS and PDS cases (Station 706207).
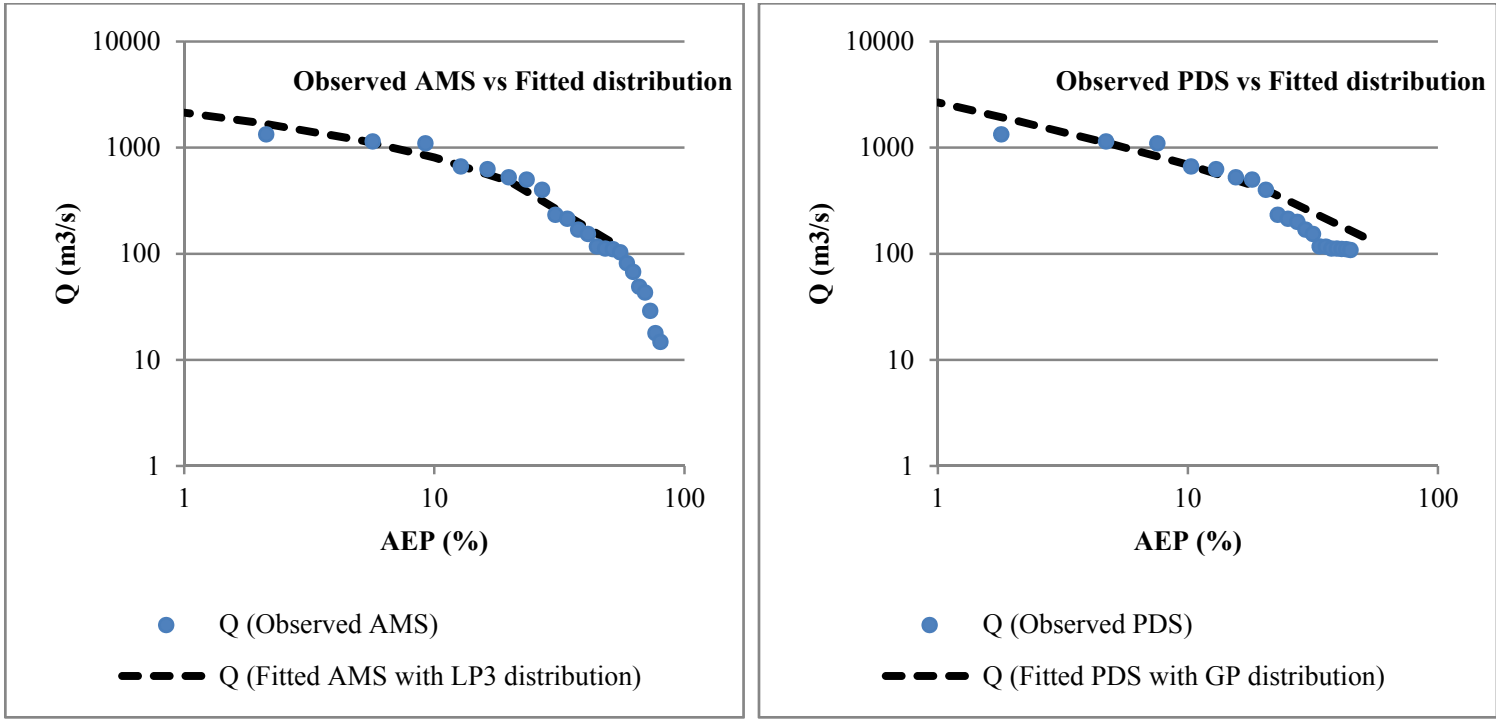

Figure 2. Fitted probability distributions for AMS and PDS cases (Station 709010).

Results of regression analysis in relation to the development of the prediction equation for $10 \%$ AEP flood $\left(Q_{10}\right)$ are summarised in Table 2. It can be seen that the developed regression equations have coefficient of determination $\left(R^{2}\right)$ values above $90 \%$ and the standard error of estimate values are quite low. The predictor variables (catchment area and the design rainfall intensity) are found to be statistically significant in both the equations with the $p$-values smaller than 0.01 . The observed (estimated by at-site flood frequency analysis) vs. predicted flood quantiles by the developed RFFE models are presented in Figure 3, which shows a good agreement between the observed and predicted flood quantiles. The regression equations satisfy the least squares model assumption quite well e.g. the residuals are normally distributed.

Comparison of the median relative error (RE) values (which is estimated ignoring the sign of the RE values at individual sites) for both the models are presented in Figure 4. It can be seen that the median RE values are $42 \%$ to $56 \%$ for the PDS based RFFE model, and $23 \%$ to $46 \%$ for the AMS based RFFE model. These results reveal that AMS based RFFE model outperforms the PDS based RFFE model for all the six AEPs. 
Table 2. Summary of regression equations for $Q_{10}$

\begin{tabular}{|c|ccc|ccc|}
\hline Model & \multicolumn{3}{|c|}{ AMS } & \multicolumn{3}{c|}{ PDS } \\
\hline $\begin{array}{c}\text { Dependent } \\
\text { variable }\end{array}$ & \multicolumn{3}{|c|}{$\log 10\left(\mathrm{Q}_{10}\right)$} & \multicolumn{3}{c|}{$\log 10\left(\mathrm{Q}_{10}\right)$} \\
\hline $\mathrm{N}$ & \multicolumn{3}{|c|}{11} & \multicolumn{3}{c|}{11} \\
\hline Independent & Coeffici & SE of & $t$-statistics $(P$ & Coeffici & SE of & $t$-statistics $(P$ \\
variables & ents & coefficients & value) & ents & coefficients & value $)$ \\
Constant & -2.597 & 0.485 & $-5.35(0.001)$ & -2.331 & 0.4763 & $-4.89(0.001)$ \\
$\log 10(\mathrm{~A})$ & 0.549 & 0.066 & $8.32(0.000)$ & 0.479 & 0.065 & $7.40(0.000)$ \\
$\log 10(\mathrm{I} 6$ 6_50\%) & 4.04 & 0.595 & $6.79(0.000)$ & 3.921 & 0.584 & $6.71(0.000)$ \\
\hline
\end{tabular}

\section{Model}

performance

$\begin{array}{ccc}R^{2} & 95.20 \% & 94.50 \% \\ \text { Adj. } R^{2} & 94.00 \% & 93.10 \% \\ \text { SEE } & 0.221 & 0.217\end{array}$

Note: AMS: Annual maximum series, RFFE: Regional flood frequency estimation, N: Number of sites, SE: standard error, SEE: standard error of estimate; $\mathrm{A}=$ catchment area $\left(\mathrm{km}^{2}\right)$; I_6_50\% = design rainfall intensity in $\mathrm{mm} / \mathrm{h}$ for 6-hour duration and $50 \%$ AEP.
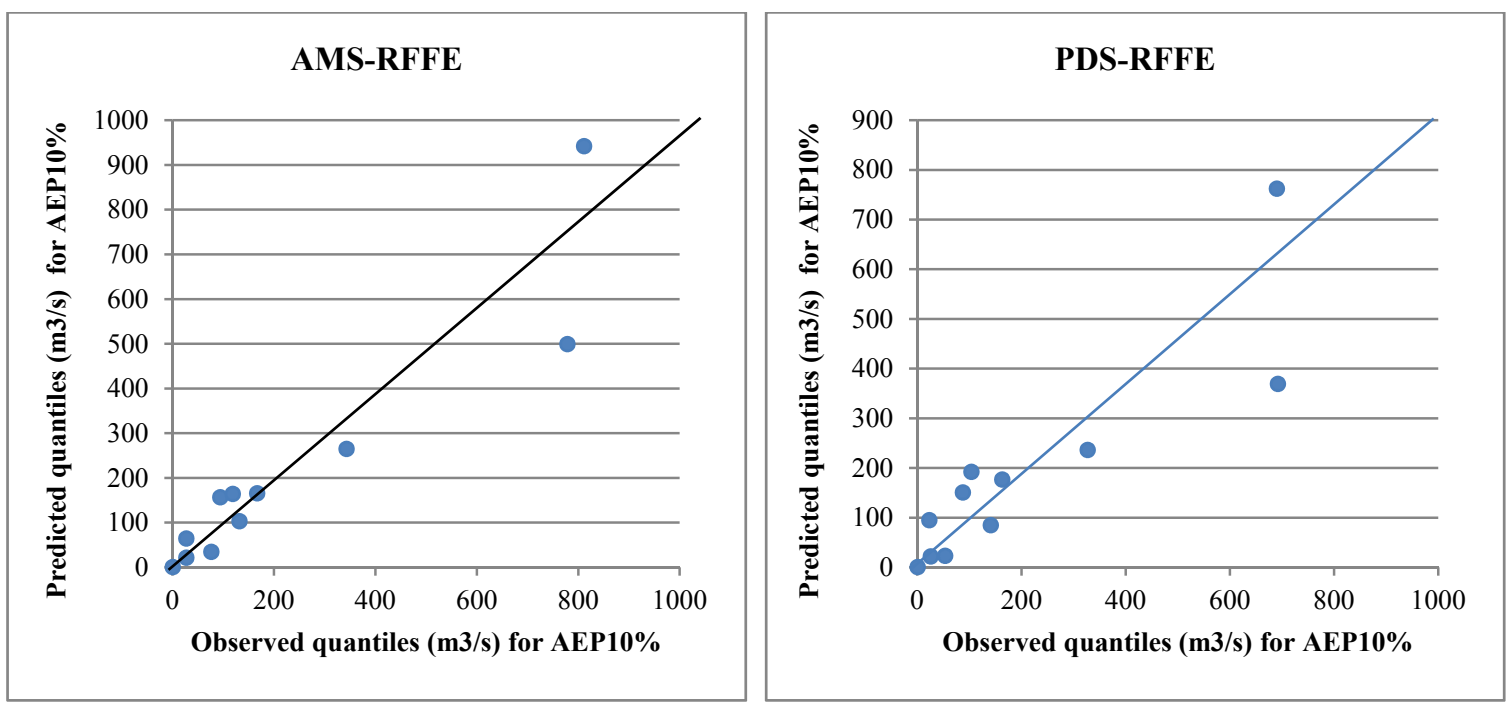

Figure 3. Observed (estimated at-site flood quantiles) vs. predicted flood quantiles for 10\% AEP.

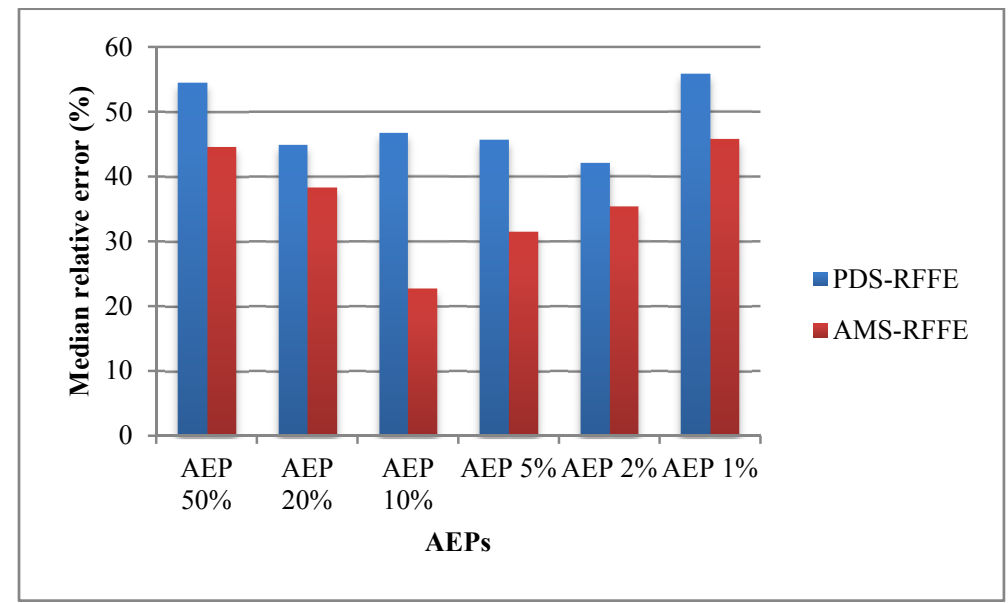

Figure 4. Comparison of median relative error values for the two RFFE models. 


\section{CONCLUSION}

Regional flood estimation models have been developed for the Pilbara arid area in Western Australia using data from eleven gauged catchments. At-site flood frequency analysis is undertaken using the AMS and PDS flood data. The regression equations for the index flood (10\% AEP flood, $\left.Q_{10}\right)$ have $R^{2}$ values greater than $90 \%$. It has been found that the median relative error values are in the range of $42 \%$ to $56 \%$ for the PDS based RFFE model and $23 \%$ to $46 \%$ for the AMS based RFFE model. These results reveal that the AMS based RFFE model outperforms the PDS based RFFE model. Therefore, the AMS based RFFE model is finally selected to recommend in the upcoming Australian Rainfall and Runoff.

The RFFE technique for the Pilbara region is based on a very small number of gauged catchments spanning a large area. There is a notable variation in catchment conditions over this region. It is therefore likely that the gauges are not fully representative of the wide range of conditions encountered in the region. Hence, the flood estimates in the arid areas given by the RFFE model should be used with caution. Users need to compare local catchment conditions with those at gauged locations and in many cases may need to adjust RFFE model estimates to account for the local catchment conditions.

\section{ACKNOWLEDGEMENTS}

ARR Revision Project 5 was made possible by funding from the Federal Government through the Department of Climate Change and Energy Efficiency and Geoscience Australia. The authors would like to acknowledge various agencies in Australia for supplying data: Australian Bureau of Meteorology, Department of Environment, Climate Change and Water (NSW), Department of Water (WA) and Niel Coles, Robin Connolly, Jim Davis, Jerome Goh, David Kemp, Leanne Pearce, Mark Pearcey, Simon Rodgers, John Ruprecht, Mohammad Bari, Patrick Thomson, Mohammad Zaman, Melanie Loveridge, Mark Babister, James Ball and Erwin Weinmann.

\section{REFERENCES}

Cordery, I. (2004). Arid zone surface runoff - a significant resource in Australia. Australian Journal of Water Resources, 8 (1), 37-43.

Davies, J.R., and Yip, E. (2014). Pilbara regional flood frequency Analysis. $35^{\text {th }}$ Hydrology and Water Resources Symposium, Perth, 24-27 February, 2014, 182-189.

Flavell, D. (2012). Design flood estimation in Western Australia. Australian Journal of Water Resources, 16(1), 1-20.

Haddad, K., and Rahman, A. (2012). Regional flood frequency analysis in eastern Australia: Bayesian GLS regression-based methods within fixed region and ROI framework - Quantile Regression vs. Parameter Regression Technique. Journal of Hydrology, 430-431, 142-161.

Haque, M.M., Rahman, A., and Haddad, K. (2014). Rating curve uncertainty in flood frequency analysis: A quantitative assessment. Journal of Hydrology and Environment Research, 2(1), 50-58.

HVAC\&R Nation (2015). The wild west. An AIRAH publication, issue 80, www.hvacrnation.com.au.

Institution of Engineers Australia (I. E. Aust.) (1987). Australian Rainfall and Runoff: A Guide to Flood Estimation, Editor: D.H. Pilgrim, Vol.1, Institution of Engineers Australia, Canberra.

Kuczera, G, (2001). Bayesian Flood Frequency Analysis Software (Version 4.50), School of Engineering, University of Newcastle, NSW, http://www.arr.org.au/wp-content/uploads/2013/Draft_Chapters/ARR IV2.pdf.

Micevski, T., Hackelbusch, A., Haddad, K., Kuczera, G., Rahman, A. (2015). Regionalisation of the parameters of the log-Pearson 3 distribution: a case study for New South Wales, Australia, Hydrological Processes, 29, 2, 250-260.

Palmen LB and Weeks WD (2011), Regional flood frequency for Queensland using the quantile regression technique, Australian Journal of Water Resources, 15, 1, 47-57.

Pilgrim, D.H., Chapman, T.G., and Doran, D.G. (1988). Problems of rainfall-runoff modelling in arid and semiarid regions. Hydrological Sciences Journal, 33(4), 379-400.

Rahman, A., Haddad, K., Kuczera, G., and Weinmann, E. (2009). Australian Rainfall and Runoff Revision Project 5: Regional Flood Methods. Stage 1 report, Engineers Australia.

Rahman, A., Haddad, K., Zaman, M., Kuczera, G., and Weinmann, P.E. (2011). Design flood estimation in ungauged catchments: A comparison between the Probabilistic Rational Method and Quantile Regression Technique for NSW. Australian Journal of Water Resources, 14(2), 127-137.

Rahman, A., Haddad, K., Zaman, M., Ishak, E., Kuczera, G., and Weinmann, P.E. (2012a). Australian Rainfall 
Haque et al., Development of a regional flood frequency estimation model for Pilbara, Australia

and Runoff Revision Projects, Project 5 Regional flood methods, Stage 2 Report.

Rahman, A., Zaman, M., Haddad,K., Kuczera, G., Weinmann,E., Weeks, W., Rajaratnam,L., and Kemp,D. (2012b). Development of a New Regional Flood Frequency Analysis Method for Semi-arid and Arid Regions of Australia. 34 th Hydrology and Water Resources Symposium, Sydney 2012, 1433- 1440.

Rahman, A., Haddad, K., Haque, M.M, Kuczera, G., and Weinmann, P.E. (2015). Australian Rainfall and Runoff Project 5: Regional flood methods: Stage 3 Report, Technical Report, No. P5/S3/025, Engineers Australia, Water Engineering, 134pp.

Reeves, J.M., De Deckker, P., and Halse, S. (2007). Groundwater ostracods from the arid Pilbara region of northwestern Australia: distribution and water chemistry. Hydrobiologia, 585, 99-118.

Ruprecht, J. (1996). Arid zone hydrology: Pilbara regions of Western Australia. 23 ${ }^{\text {rd }}$ Hydrology and Water Resources Symposium, Hobart, Australia, 21-24 May, 1996, 301-305.

Weeks, W., Babister, M.,Ball, J., and Retallick, M. (2015). Testing new design flood estimation techniques for catchments across Australia. E-proceedings of the $36^{\text {th }}$ IAHR World Congress 28 June - 3 July, 2015, The Hague, the Netherlands.

Zaman, M., Rahman, A., and Haddad, K. (2012). Regional flood frequency analysis in arid regions: A case study for Australia. Journal of Hydrology, 475, 74-83 